\title{
Perspectives
}

\section{Hypercalcemia of Malignancy Revisited}

\author{
Gregory R. Mundy \\ Division of Endocrinology and Metabolism, University of Texas Health Science Center, San Antonio, Texas 78284
}

In the three years since the last Perspectives article in the Journal of Clinical Investigation on this topic (1), there have been major advances in our understanding of the heterogeneous mechanisms responsible for the hypercalcemia of malignancy. Reports of many of these advances have appeared in the pages of the Journal of Clinical Investigation. These advances include discovery and characterization of the PTH-related protein (PTH-rP) ${ }^{1}$ produced by many solid tumors, demonstration of tumor-derived transforming growth factor-alpha (TGF-alpha) as a bone-resorbing factor that can cause hypercalcemia, identification of lymphotoxin as the major mediator of bone destruction in myeloma, and definitive demonstration of increased renal tubular reabsorption of calcium in hypercalcemia associated with solid tumors.

One concept that has not changed in these last three years is that the mechanisms responsible for hypercalcemia of malignancy are heterogeneous. Different patterns of disturbances in calcium homeostasis occur in different types of malignancy. A simple diagram illustrating some of these different patterns is shown in Fig. 1. In all of the examples provided, increased bone resorption is an important feature. However, the importance of the net fluxes of calcium that occur across the other two major organs that guard calcium homeostasis (gut and kidney) depend on the type of tumor.

\section{PTH-related protein (PTH-rP) and solid tumors}

In the last 12 months, a succession of papers has described a protein isolated from solid tumors that has significant sequence homology in the $\mathrm{NH}_{2}$-terminal region to PTH. It was first suggested by Albright almost 50 years ago that hypercalcemia of malignancy could be related to PTH or a PTH-like peptide, but it was not appreciated just how PTH-like this factor was until it was purified from a variety of tumor cell lines and molecularly cloned (2-6). This protein is composed of 141 amino acids, with 8 of the first 13 residues identical to those of human PTH. Since the $\mathrm{NH}_{2}$-terminal region of the PTH molecule is responsible for biologic activity and binding to the PTH receptor, it is not surprising that PTH-rP mimics the effects of PTH by binding to and activating the PTH re-

Address reprint requests to Dr. Gregory R. Mundy, Division of Endocrinology and Metabolism, University of Texas Health Science Center, 7703 Floyd Curl Drive, San Antonio, TX 78284.

Received for publication 18 February 1988 and in revised form 5 April 1988.

1. Abbreviations used in this paper: PTH-rP, PTH-related protein; TGF, transforming growth factor; TNF, tumor necrosis factor.

J. Clin. Invest.

(c) The American Society for Clinical Investigation, Inc.

0021-9738/88/07/0001/06 \$2.00

Volume 82, July 1988, 1-6 ceptor (3). Synthetic peptides that correspond to the $\mathrm{NH}_{2}$-terminal end of PTH-rP have now been tested in vitro and in vivo; these peptides appear to have effects essentially identical to those of PTH on the kidney and bone (7-12). Synthetic peptide analogues of PTH-rP enhance osteoclastic bone resorption in vitro $(7,9,10)$, enhance renal tubular calcium reabsorption $(7,9)$, and cause hypercalcemia in vivo (8-10). Differences in potency with PTH have been suggested (7), although these have not been found by other workers (8-10).

These observations provoke obvious questions about the normal physiologic role of this protein and its relationship to PTH and to the PTH receptor. The immediate question is whether this protein explains all of the manifestations of hypercalcemia of malignancy in patients with solid tumors. Based on current data, this is unlikely. The syndrome of humoral hypercalcemia of malignancy associated with solid tumors is quite distinct from that of primary hyperparathyroidism, and cannot be explained simply by what is known of the effects of synthetic peptides of PTH-rP on kidney, bone, and gut. For example, osteoclastic bone resorption is much more prominent in humoral hypercalcemia of malignancy than in primary hyperparathyroidism, bisphosphonate therapy is more effective in lowering the serum calcium, and available information suggests rates of bone formation are reduced. There are also differences in the renal tubular function of the two syndromes. Patients with primary hyperparathyroidism have normal or increased 1,25 dihydroxyvitamin $\mathrm{D}$ production, which is probably a consequence of increased PTH and lowered ambient phosphate concentrations. However, in the hypercalcemia of malignancy, even when PTH-rP is produced by the tumor, 1,25 dihydroxyvitamin $\mathrm{D}$ production is usually suppressed (13) and patients tend to be alkalotic, rather than hyperchloremic and mildly acidotic, as is the case in primary hyperparathyroidism (14). How can these differences be explained? One possibility is that the full-length molecule behaves differently from the synthetic peptide. However, it is unlikely that opposite effects (e.g., decreased bone formation and decreased 1,25 dihydroxyvitamin $\mathrm{D}$ production) will be explained in this way. A more likely possibility is that the effects of the PTH-rP on target organs are modified by other factors, such as TGF-alpha, IL-1, and tumor necrosis factor (TNF). These factors are all more powerful bone-resorbing factors than PTH in vivo $(9,15)$ and in vitro $(16)$. Each increases plasma calcium $(15,17,18)$. Evidence for the role of these factors was discussed in more detail in the earlier Perspectives article on this topic (1). Since these factors are often produced by tumors, which also produce PTH-rP, hypercalcemia in these circumstances is probably due to the combined effects of PTH-rP and these factors on target organs. These factors act synergistically with PTH (and probably also with PTH-rP) to stimulate bone resorption in vitro (19) because their major effect is to stimulate proliferation of osteoclast 

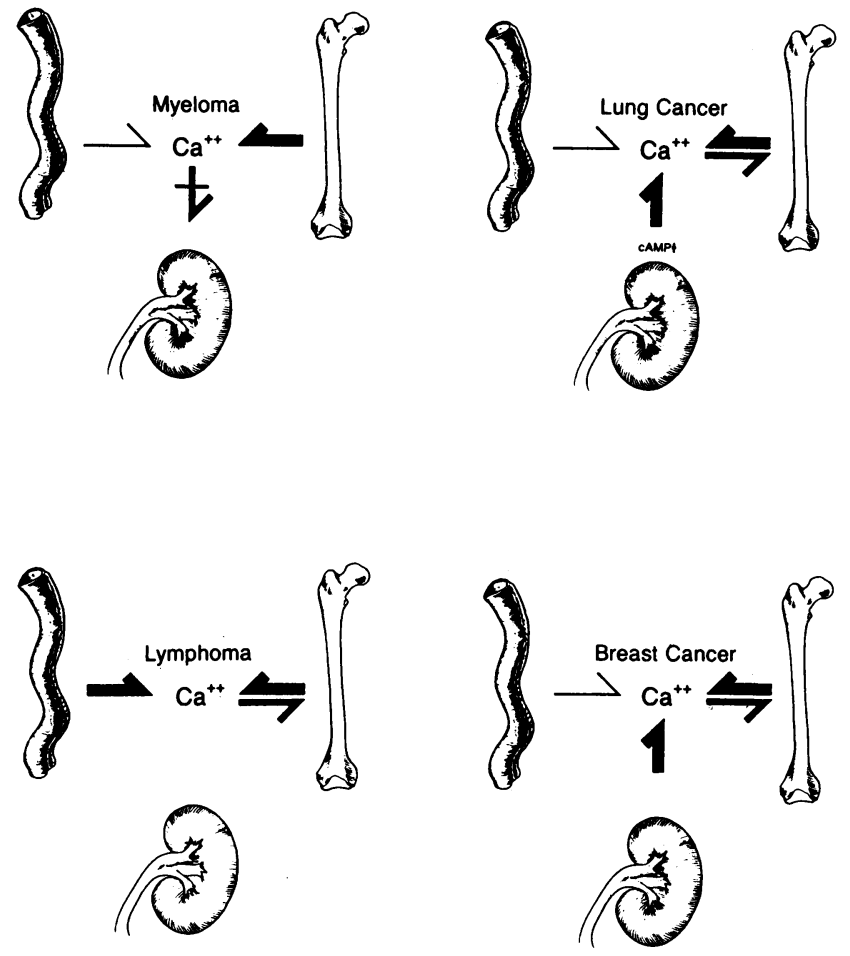

Figure 1. The heterogeneous pattern of abnormalities in calcium homeostasis found in patients with the hypercalcemia of malignancy. In myeloma, increased bone resorption is associated with decreased glomerular filtration. In patients with solid tumors such as lung cancer, increased bone resorption and increased renal tubular calcium reabsorption occur, and are associated with increased nephrogenous CAMP. In patients with breast cancer, increased bone resorption and increased renal tubular calcium reabsorption also occur, but this tumor is not usually associated with increased nephrogenous cAMP, and is almost always associated with metastatic bone disease. In lymphomas, increased bone resorption occurs together with, in some cases, increased gut absorption of calcium. The potential mechanisms responsible for these derangements are described in the text. Reproduced from Kidney International, 1987. 31:142-155, published with permission.

progenitors (20), whereas PTH affects cells that are later in the osteoclast lineage. However, the effects of PTH (and presumably PTH-rP) on some target cells may also be substantially impaired by these factors. For example, TGF-alpha, IL-1, and TNF all decrease adenylate cyclase responsivity to PTH in cultured osteoblastic cells (21), and it is likely they will have the same effects on these responses to PTH-rP.

Another question is whether the complete protein will have other functions, possibly by interacting with another receptor distinct from that of PTH. The answer to that question may have to await availability of preparations of the recombinant protein. The PTH-rP shares 8 of the first 13 amino acids with PTH, but thereafter there is no sequence homology. Although PTH (1-84) behaves similarly to PTH (1-34) in biological assays, PTH-rP has a basic amino acid carboxyl terminus of 57 residues that could well mediate other biological effects.

According to the data of Moseley and co-workers (22), PTH-rP is produced very commonly by many solid tumors. For example, the majority of squamous cell cancers of the skin and normal skin cells contain PTH-related peptide as detected by immunofluorescent techniques. Since PTH-rP is not associated with hypercalcemia in these cases, it is likely that the tumors do not secrete sufficient amounts of the PTH-rP to disrupt calcium homeostasis. Could PTH-rP have a normal physiological function on calcium or phosphate homeostasis? This does not appear likely in postnatal life, unless the normal tissue source is the parathyroid glands. Patients with parathyroid gland disease or ablation have hypocalcemia and hyperphosphatemia, indicating that a normal tissue source outside the parathyroids does not produce enough PTH-rP to prevent the features of hypoparathyroidism. It is conceivable, however, that PTH-rP is an alternative form of PTH produced in the parathyroid glands themselves. If so, it could be responsible for some cases of primary hyperparathyroidism. There are a few patients with primary hyperparathyroidism in whom increased serum-immunoreactive PTH concentrations cannot be detected. Another possibility is that PTH-rP, like some other tumor products, represents a fetal hormone, affecting calcium homeostasis before birth, and preliminary evidence suggests that PTH-rP derived from the fetal parathyroid glands may influence placental calcium transport in fetal lambs (23).

One point to emphasize is that although the PTH-rP is found frequently in solid tumors, there is no evidence as yet that PTH itself is produced by any tumors except those arising from the parathyroid glands (24). It has been suggested that assays used in earlier studies showing increased serum-immunoreactive PTH in patients with malignancy (25) were in fact recognizing PTH-rP. This does not explain how these results were also obtained in patients in whom PTH-rP is not produced, such as patients with myeloma. Moreover, the similarities in the molecules are not in the regions best recognized by these older assays. An alternative explanation for the spurious immunoassay results may be that the suppressed parathyroid glands release immunoreactive but biologically inert PTH fragments.

The relationship of the PTH-rP gene to that for PTH itself should soon be known. It has recently been reported by Mangin et al. (6) that PTH-rP is encoded by human chromosome 12 , whereas the PTH gene has previously been mapped to chromosome 11. PTH-rP thus cannot be the result of alternate splicing of the PTH gene. Mangin et al. (6) do however report multiple forms (at least three) of PTH-rP mRNA. One of their cDNAs may encode an alternately spliced message that could give rise to a second PTH-rP, with a novel carboxy-terminal portion, thus bearing the same relation to PTH-rP that calcitonin gene-related protein does to calcitonin (perhaps a PTHrP gene-related protein). It is likely that both PTH and PTH-rP arose from a single ancestral gene that duplicated and separated during evolution, such as is the case with epidermal growth factor and TGF-alpha. These answers should be clearer when the complete gene sequence is published.

\section{Lymphotoxin and myeloma}

New proteins are being identified not only in solid tumors associated with hypercalcemia, but also in the hematologic malignancies. In myeloma, it has long been known that the malignant plasma cells produce a local cytokine that stimulates osteoclast activity (26). Recently, the immune cell products lymphotoxin, TNF, and IL-1 have each been identified as potent stimulators of osteoclastic bone resorption in vitro (27, 28). Similar activity is produced by normal activated immune cells (for review and bibliography, see reference 1). Although 
the majority of bone-resorbing activity produced by normal activated leukocytes is IL-1 beta (29), it is now apparent that the major bone-resorbing cytokine expressed by those human myeloma cells so far studied is lymphotoxin (also called TNF beta). The bone-resorbing activity produced by five cultured myeloma cell lines in vitro was substantially inhibited by neutralizing antibodies to lymphotoxin (30). Moreover, lymphotoxin causes hypercalcemia when infused or injected in vivo (30). Lymphotoxin is normally produced by activated T lymphocytes. It binds to the same receptor as TNF, with which it shares identical biological properties. Its biological properties also overlap with many of those of IL-1. This group of molecules may be responsible for other ectopic hormone syndromes in patients with cancer, including cachexia, hypertriglyceridemia, and probably anemia due to suppression of erythropoiesis. These cytokines not only stimulate proliferation of osteoclast progenitors (31), but also activate the mature multinucleate cells, albeit indirectly (32). However, like PTHrP produced by solid tumors, production of lymphotoxin by myeloma cells does not alone account for the hypercalcemic syndrome in myeloma. Not all of the bone-resorbing activity produced by myeloma cells can be blocked by antisera to lymphotoxin (30), and it appears likely that other bone-resorbing factors that remain to be identified are also produced by myeloma cells.

Interestingly, human myeloma cells constitutively express mRNA for both lymphotoxin and TNF (30). However, TNF is not released by the cells. Presumably, there is inhibition of translation or secretion of the protein.

Production of potent bone-resorbing cytokines by neoplastic immune cells may represent an aberration of the mechanisms that regulate normal osteoclastic bone resorption. Bone is normally remodeled in discrete units or packets throughout the skeleton, and the cellular events involved in remodeling are likely to be controlled by local factors produced in the microenvironment of remodeling surfaces. Normal immune cells that produce potent osteotropic cytokines such as lymphotoxin, IL-1, TNF, gamma-IFN, and TGF beta may occupy a pivotal role in the regulation of normal bone remodeling.

\section{Relative roles of the kidney and bone in humoral hypercalcemia}

The major organs involved in disruptions of calcium homeostasis in hypercalcemia of malignancy are bone and kidney. Their relative importance is controversial. Bone resorption has always been considered the major cause by most American investigators, but that position has been strongly challenged recently. European investigators have long considered that the major organ responsible for hypercalcemia in primary hyperparathyroidism is the kidney, which they believe to play an important and underappreciated role in the hypercalcemia of malignancy as well. The earliest observations were based on clinical studies (33), which showed that renal calcium excretion was usually less than expected for the degree of hypercalcemia. Most patients with hypercalcemia of malignancy (myeloma is a notable exception) have increased renal tubular reabsorption of calcium, similar to those with primary hyperparathyroidism. These observations have been criticized on the grounds that impaired volume status could promote calcium reabsorption, and this could be the explanation for impaired calcium excretion. However, Bonjour and his coworkers recently showed in the rat Leydig cell tumor model of the humoral hypercalcemia of malignancy, that reabsorption of calcium was increased in the renal tubules in circumstances in which sodium and volume status were carefully controlled. They then showed that the radioprotective agent WR-2721, which inhibits renal tubular calcium reabsorption, lowered serum calcium at the same time as it increased renal calcium excretion (34). The only conclusion from these observations can be that renal tubular calcium reabsorption plays an important role in the pathophysiology of the humoral hypercalcemia in this model. This conclusion has been strengthened recently by observations that synthetic peptides of PTH-rP (1-34) increase renal tubular calcium reabsorption in vivo (9), and Leydig tumor cells are known to produce a PTH-rP (35). A different mechanism for increasing renal tubular calcium reabsorption has been proposed by Bijvoet and his colleagues (36). This group has gained enormous experience over the years with the agent 3 amino-1-hydroxypropylidine-1,1-bisphosphonate (APD), a bisphosphonate that specifically inhibits bone resorption. They argue that since APD is remarkably effective in lowering serum calcium in hypercalcemia of malignancy ( $>95 \%$ of patients respond), increased bone resorption must be the major pathogenetic mechanism responsible for hypercalcemia. Bijvoet and co-workers also argue that a component of increased renal tubular calcium reabsorption exists, but suggest that this occurs not as a consequence of a tumor factor but rather because of the natriuretic effect of hypercalcemia that leads to volume depletion. As a consequence, proximal tubular reabsorption of calcium, sodium, and fluid are enhanced. Sodium loading restores extracellular fluid volume and reduces enhanced reabsorption of sodium and calcium in the proximal tubules, which is due to this mechanism. However, when urinary sodium excretion exceeds $4 \mathrm{mmol} / \mathrm{liter}$ glomerular filtrate (fractional excretion of sodium $\sim 3 \%$ ), the effects of a humoral factor on calcium reabsorption in the distal tubules will also be obscured (37), because excessive natriuresis markedly enhances distal delivery of calcium so that reabsorptive capacity at that site is exceeded (37). Under conditions of vigorous sodium loading, the effects of a humoral factor thus may not be apparent and increased renal tubular calcium reabsorption will be lowered whether it is due to a humoral factor or to volume depletion caused by the natriuretic effect of hypercalcemia.

The kidney is also important in the hypercalcemia of myeloma. In patients with myeloma who develop hypercalcemia, there is almost always some fixed impairment of renal function (38) that may have multiple causes. In this case, hypercalcemia results from increased bone resorption associated with decreased glomerular filtration and decreased capacity of the kidney to clear the calcium load from the extracellular fluid.

Increased osteoclastic bone resorption is obviously an important mechanism in the pathophysiology of hypercalcemia of malignancy, since hypercalcemia is improved by drugs that specifically inhibit bone resorption and increased osteoclast activity is usually a prominent morphologic abnormality. However, Ralston and co-workers (39) have recently questioned whether this increased bone resorption is important in early hypercalcemia and whether it is factor mediated. Using histomorphometric studies, they argue that hypercalcemia can occur in patients with malignancy without detectable changes in bone morphology and specifically osteoclastic resorption. Their suggestion is that the tumor factors act on the kidney to promote renal tubular calcium reabsorption, and bone resorp- 
tion becomes important only later in the disease when the patient is sicker and immobile. It should be appreciated that the morphologic changes in bone in patients with malignancy and hypercalcemia are not those seen in primary hyperparathyroidism, but are consistent with those seen in early stages of immobilization. For example, osteoclastic bone resorption is more prominent, subperiosteal resorption is extremely rare, and there is no evidence of increased bone formation or bone turnover, which is characteristic of florid cases of primary hyperparathyroidism. Although immobilization may play a role in promoting osteoclastic bone resorption, it is not likely to be the only or even major mechanism for bone resorption. Fully mobile animals carrying hypercalcemic tumors have prominent osteoclastic bone resorption. Moreover, in vitro studies usually show that tumors associated with hypercalcemia secrete factors that are potent stimulators of osteoclastic bone resorption.

Both increased bone resorption and impaired renal calcium excretion are clearly important in the pathophysiology of hypercalcemia, and their combined effects on serum calcium are probably synergistic. For example, a patient with substantially increased bone resorption alone may remain normocalcemic since renal calcium excretion will be enhanced, because PTH is suppressed. However, if a tumor secretes factors that in addition to stimulating bone resorption also inhibit the fractional excretion of calcium, hypercalcemia will occur more readily. Questioning whether bone resorption or renal tubular calcium reabsorption are mediated by factors or other mechanisms is useful, but the important issue is the relative importance of bone resorption compared with renal calcium excretion, and whether therapy should be tailored to the pathophysiologic mechanism. Unfortunately, the experimental approaches that are currently being used to distinguish the relative importance of bone and kidney in hypercalcemia (such as testing effects of tumor factors on plasma calcium after total nephrectomy) are too imprecise to provide this information.

\section{Other problems to be solved}

Breast cancer and other tumors associated with osteolytic metastases. Approximately $25 \%$ of unselected hypercalcemic patients with malignant disease have breast cancer (40), making it the most common hypercalcemic malignancy after lung cancer. Hypercalcemia in breast cancer occurs most commonly when there is widespread osteolytic bone destruction and in the late phases of the disease. Bone destruction is probably osteoclastic and occurs locally around metastatic tumor deposits, although cultured human breast cancer cells also have the capacity to resorb bone (41). The factors responsible for this bone resorption are far from clear. The majority of breast cancers do not produce PTH-rP (12). In some cases, it is possible that prostaglandins are involved as local stimulators of osteoclasts (42). Certainly, cultured human breast cancer cells release bone-resorbing prostaglandins when exposed to estrogens or antiestrogens (43). However, indomethacin and similar prostaglandin synthesis inhibitors have been notoriously ineffective as therapies for either metastatic bone disease in breast cancer or hypercalcemia. There are numerous other osteotropic factors produced by breast cancer cells that could be important, including TGF alpha, TGF beta, and plateletderived growth factor, each of which can stimulate bone resorption. Whether any of these proteins has a role in the bone destruction or hypercalcemia associated with breast cancer remains to be shown. Increased renal tubular calcium reabsorption may also contribute to hypercalcemia in breast cancer (44), although the mechanism responsible is unknown. Clearly, breast cancer is an area ripe for investigation for hypercalcemia-inducing factors.

Lymphomas. In a few cases of lymphoproliferative disease (Hodgkin's disease, B cell lymphomas, and T cell lymphomas) associated with hypercalcemia, serum 1,25 dihydroxyvitamin $\mathrm{D}$ is increased (45). In these patients, gut absorption of calcium, when measured, is also increased. The source of 1,25 dihydroxyvitamin $\mathrm{D}$ is likely to be the tumor cells themselves, since lymphoid cells transformed with the human $\mathrm{T}$ cell lymphotrophic virus-type I (which is one cause of adult $T$ cell lymphoma) have now been found to metabolize 25 hydroxyvitamin to 1,25 dihydroxyvitamin $D(46)$. Increased serum 1,25 dihydroxyvitamin $D$ is an unusual finding that appears in only a minority of hypercalcemic patients with lymphoproliferative disorders. Even in those in whom increased 1,25 dihydroxyvitamin D is present, coincidental mechanisms such as the production of bone-resorbing cytokines by the lymphoid cells may be at least equally important.

1,25 dihydroxyvitamin $\mathrm{D}$ has unique effects on bone resorption. It causes differentiation of committed progenitors into cells with the characteristics of mature osteoclasts in vitro (47). 1,25 dihydroxyvitamin D has many other immunomodulatory effects on $T$ cells and cytokine production in the marrow environment (48). Its production by transformed lymphocytes raises the possibility that it might also be produced by normal lymphocytes in the bone microenvironment under appropriate circumstances.

Others. There are other factors and potential mechanisms that could be responsible for the hypercalcemia of malignancy that have not yet been thoroughly investigated. These include the production of IL-1 and other cytokines by solid tumors or even normal cells in response to the presence of a tumor metastasis. As part of the host defense response to the presence of a tumor, normal immune cells may attempt to limit growth of the tumor by releasing cytokines that influence tumor growth and produce other paraneoplastic syndromes such as cachexia and hyperpyrexia. Possibly hypercalcemia is another, since these cytokines can also increase plasma calcium $(15,18,30)$.

A number of tumors have been described that cause leukocytosis in association with hypercalcemia. These are frequently squamous cell carcinomas of the head and neck, and many of these tumors produce colony-stimulating factors and bone-resorbing factors, and cause a hypercalcemia-leukocytosis syndrome in nude mice (49). The colony-stimulating factors associated with the leukocytosis syndrome are probably not identical with the bone-resorbing factors responsible for increasing osteoclast activity.

Two recent reviews have focused attention on the complexities of calcium homeostasis and the oversimplified traditional view of the system as one of simple reactive regulation by systemic hormones controlled by negative feedback. Parfitt (50) and Staub et al. (51) have drawn attention to the importance of the intrinsic self-oscillatory mechanism that is responsible for maintenance of plasma calcium even in the absence of hormones, and which is mediated by exchange of calcium between the bone fluid and the extracellular fluid. This calcium exchange depends on the lining cells that cover quiescent bone surfaces, and occurs independent of osteoclastic bone 
resorption and bone formation. Nothing is yet known of the effects of tumors or tumor factors on the exchange of calcium between the bone fluid and the extracellular fluid.

In conclusion, hypercalcemia of malignancy is an exciting area that is changing rapidly. Modern techniques in protein purification and molecular biology have effectively identified tumor-associated proteins that are involved in the syndromes of hypercalcemia associated with malignancy. These studies have improved our understanding not only of tumor biology and the production of tumor-associated proteins, but also our understanding of normal calcium homeostasis and the physiological factors that regulate osteoclastic bone resorption and renal tubular calcium handling. Identification of the factors should be followed by studies of their relative biological significance. The most important challenges now facing investigators in this area will be to develop adequate biological systems to test the effects of these factors on calcium homeostasis in vivo and to determine the relative importance of their actions on the various limbs of the homeostatic system.

\section{Acknowledgments}

I am grateful to Nancy Garrett for her help in the preparation of this review. I am also grateful to my colleagues Lynda Bonewald, Brendan Boyce, John Chirgwin, James Dunn, Gloria Gutierrez, Michael Katz, James Poser, David Roodman, Massimo Sabatini, Peter Smolens, Katherine Tuttle, Ashley Yates, and Toshiyuki Yoneda for helpful discussions.

Some of the data reviewed in this paper have been gathered with support from National Institutes of Health grants CA-40035, AR-28149, and RR-1346.

\section{References ${ }^{2}$}

1. Mundy, G. R., K. J. Ibbotson, and S. M. D'Souza. 1985. Tumor products and the hypercalcemia of malignancy. J. Clin. Invest. 76:391-395.

2. Suva, L. J., G. A. Winslow, R. E. H. Wettenhall, R. G. Hammonds, J. M. Moseley, H. Diefenbach-Jagger, C. P. Rodda, B. E. Kemp, H. Rodriguez, E. Y. Chen, P. J. Hudson, T. J. Martin, and W. I. Wood. 1987. A parathyroid hormone-related protein implicated in malignant hypercalcemia: cloning and expression. Science (Wash. DC). 237:893-896.

3. Strewler, G. J., P. H. Stern, J. W. Jacobs, J. Eveloff, R. F. Klein, S. C. Leung, M. Rosenblatt, and R. A. Nissenson. 1987. Parathyroid hormone-like protein from human renal carcinoma cells. Structural and functional homology with parathyroid hormone. J. Clin. Invest. 80:1803-1807.

4. Moseley, J. M., M. Kubota, H. Diefenbach-Jagger, R. E. H. Wettenhall, B. E. Kemp, L. J. Suva, C. P. Rodda, P. R. Ebeling, P. J. Hudson, J. D. Zajac, and T. J. Martin. 1987. Parathyroid hormonerelated protein purified from a human lung cancer cell line. Proc. Natl. Acad. Sci. USA. 84:5048-5052.

5. Stewart, A. F., T. We, D. Goumas, W. J. Burtis, and A. E. Broadus. 1987. N-terminal amino acid sequence of two novel tumorderived adenylate cyclase-stimulating proteins: identification of parathyroid hormone-like and parathyroid hormone-unlike domains. Biochem. Biophys. Res. Commun. 146:672-678.

6. Mangin, M., A. C. Wegg, B. E. Dreyer, J. T. Posillico, K. Ideda, D. E. Barton, U. Francke, and A. E. Broadus. 1988. Identification of a cDNA encoding a parathyroid hormone-like peptide from a human

2. It has not been possible within the context of a Perspectives article to reference all of the important work in this field, particularly before the last several years. A more complete bibliography can be found in references 1,14 , and 37 . tumor associated with a humoral hypercalcemia of malignancy. Proc. Natl. Acad. Sci. USA. 85:597-601.

7. Kemp, B. E., J. M. Moseley, C. P. Rodda, P. R. Ebeling, R. E. H. Wettenhall, D. Stapleton, H. Diefenbach-Jagger, F. Ure, V. P. Michelangeli, H. A. Simmons, L. G. Raisz, and T. J. Martin. 1987. Parathyroid hormone-related protein of malignancy: active synthetic fragments. Science (Wash. DC). 238:1568-1570.

8. Horiuchi, N., M. P. Caulfield, J. E. Fisher, M. E. Goldman, R. L. McKee, J. E. Reagan, J. J. Levy, R. F. Nutt, S. B. Rodan, T. L. Schofield, T. L. Clemens, and M. Rosenblatt. 1987. Similarity of synthetic peptide from human tumor to parathyroid hormone in vivo and in vitro. Science (Wash. DC). 238:1566-1567.

9. Yates, A. J. P., G. E. Gutierrez, P. Smolens, P. S. Travis, M. S. Katz, T. B. Aufdemorte, B. F. Boyce, T. K. Hymer, J. W. Poser, and G. R. Mundy. 1988. Effects of a synthetic peptide of a parathyroid hormone-related protein on calcium homeostasis, renal tubular calcium reabsorption, and bone metabolism. J. Clin. Invest. 81:932-938.

10. Stewart, A. F., M. Mangin, T. Wu, D. Goumas, K. L. Insogna, W. J. Burtis, and A. E. Broadus. 1988. Synthetic human parathyroid hormone-like protein stimulates bone resorption and causes hypercalcemia in rats. J. Clin. Invest. 81:596-600.

11. Rodan, S. B., M. Noda, G. Wesolowski, M. Rosenblatt, and G. A. Rodan. 1988. Comparison of postreceptor effects of 1-34 human hypercalcemia factor and 1-34 human parathyroid hormone in rat osteosarcoma cells. J. Clin. Invest. 81:924-927.

12. Sartori, L., E. C. Weir, A. F. Stewart, A. E. Broadus, M. Mangin, P. Q. Barrett, and K. L. Insogna. 1988. Synthetic and partially-purified adenylate cyclase-stimulating proteins from tumors associated with humoral hypercalcemia of malignancy inhibit phosphate transport in a PTH-responsive renal cell line. J. Clin. Endocrinol. \& Metab. 66:459-461.

13. Stewart, A. F., R. Horst, L. J. Deftos, E. C. Cadman, R. Lang, and A. E. Broadus. 1980. Biochemical evaluation of patients with cancer-associated hypercalcemia: evidence for humoral and nonhumoral groups. N. Engl. J. Med. 303:1377-1383.

14. Wills, M. R., and G. K. McGowan. 1964. Plasma-chloride levels in hyperparathyroidism and other hypercalcaemic states. $\mathrm{Br}$. Med. J. 1:1153-1156.

15. Sabatini, M., B. Boyce, T. Aufdemorte, L. Bonewald, and G. Mundy. 1988. Infusions of recombinant human interleukin-1 alpha and beta cause hypercalcemia in normal mice. Proc. Natl. Acad. Sci. USA. In press.

16. Mundy, G. R. 1987. The hypercalcemia of malignancy. Kidney Int. 31:142-155.

17. Tashjian, A. H., E. F. Voelkel, W. Lloyd, R. Derynck, M. E. Winkler, and L. Levine. 1986. Actions of growth factors on plasma calcium. J. Clin. Invest. 78:1405-1409.

18. Tashjian, A. H., E. F. Voelkel, M. Lazzaro, D. Goad, T. Bosma, and L. Levine. 1987. Tumor necrosis factor-alpha (cachectin) stimulates bone resorption in mouse calvaria via a prostaglandin-mediated mechanism. Endocrinology. 120:2029-2036.

19. Dewhirst, F. E., J. M. Ago, W. J. Peros, and P. Stashenko. 1987. Synergism between parathyroid hormone and interleukin-1 in stimulating bone resorption in organ culture. J. Bone Min. Res. 2:127-134.

20. Takahashi, N., B. R. MacDonald, J. Hon, M. E. Winkler, R. Derynck, G. R. Mundy, and G. D. Roodman. 1986. Recombinant human transforming growth factor alpha stimulates the formation of osteoclast-like cells in long term human marrow cultures. J. Clin. Invest. 78:894-898.

21. Gutierrez, G. E., G. R. Mundy, R. Derynck, E. L. Hewlett, and M. S. Katz. 1987. Inhibition of parathyroid hormone-responsive adenylate cyclase in clonal osteoblast-like cells by transforming growth factor alpha and epidermal growth factor. J. Biol. Chem. 262:1584515850.

22. Moseley, J. M., B. E. Kemp, C. P. Rodda, V. P. Michelangeli, P. R. Ebeling, J. A. Danks, L. G. Raisz, and T. J. Martin. 1988. Parathyroid hormone-related protein of malignancy. Biological ac- 
tions of synthetic peptides and immunocytochemical localisation. Calcif. Tissue Int. 42 (Suppl.): 174.

23. Rodda, C. P., J. A. Heath, P. R. Ebeling, J. M. Moseley, A. D. Care, I. W. Caple, and T. J. Martin. Regulation of fetal calcium metabolism: evidence for a novel parathyroid hormone-related protein promoting placental calcium transport. J. Bone Min. Res. In press.

24. Simpson, E. L., G. R. Mundy, S. M. D'Souza, K. J. Ibbotson, R. Bockman, and J. W. Jacobs. 1983. Absence of parathyroid hormone messenger RNA in nonparathyroid tumors associated with hypercalcemia. N. Engl. J. Med. 309:325-330.

25. Benson, R. C., B. L. Riggs, B. M. Pickard, and C. D. Arnaud. 1974. Radioimmunoassay of parathyroid hormone in hypercalcemic patients with malignant disease. Am. J. Med. 56:821-826.

26. Mundy, G. R., L. G. Raisz, R. A. Cooper, G. P. Schechter, and S. E. Salmon. 1974. Evidence for the secretion of an osteoclast stimulating factor in myeloma. N. Engl. J. Med. 291:1041-1046.

27. Bertolini, D. R., G. E. Nedwin, T. S. Bringman, and G. R. Mundy. 1986. Stimulation of bone resorption and inhibition of bone formation in vitro by human tumour necrosis factor. Nature (Lond.). 319:516-518.

28. Gowen, M., O. D. Wood, E. J. Ihrie, M. K. B. McGuire, and R. G. G. Russell. 1983. An interleukin 1 like factor stimulates bone resorption in vitro. Nature (Lond.). 306:378-380.

29. Dewhirst, F. E., P. P. Stashenko, J. E. Mole, and T. Tsurumachi. 1985. Purification and partial sequence of human osteoclast-activating factor: identity with interleukin-1 beta. J. Immunol. 135:25622568 .

30. Garrett, I. R., B. G. M. Durie, G. E. Nedwin, A. Gillespie, T. Bringman, M. Sabatini, D. R. Bertolini, and G. R. Mundy. 1987. Production of the bone resorbing cytokine lymphotoxin by cultured human myeloma cells. $N$. Engl. J. Med. 317:526-532.

31. Roodman, G. D., N. Takahashi, A. Bird, and G. R. Mundy. 1987. Tumor necrosis factor alpha (TNF) stimulates formation of osteoclast-like cell (OCL) in long term human marrow cultures by stimulating production of interleukin-1 (IL-1). Clin. Res. 35:515a. (Abstr.)

32. Thomson, B. M., G. R. Mundy, and T. J. Chambers. 1987. Tumor necrosis factors alpha and beta induce osteoblastic cells to stimulate osteoclastic bone resorption. J. Immunol. 138:775-779.

33. Peacock, M., W. G. Robertson, and B. E. C. Nordin. 1969. Relation between serum and urine calcium with particular reference to parathyroid activity. Lancet. i:384-386.

34. Hirschel-Scholz, S., J. Caverzasio, R. Rizzoli, and J. P. Bonjour. 1986. Normalization of hypercalcemia associated with a decrease in renal calcium reabsorption in Leydig cell tumor-bearing rats treated with WR-2721. J. Clin. Invest. 78:319-322.

35. Rodan, S. B., K. L. Insogna, A. M. C. Vignery, A. F. Stewart, A. E. Broadus, S. M. D'Souza, D. R. Bertolini, G. R. Mundy, and G. A. Rodan. 1983. Factors associated with humoral hypercalcemia of malignancy stimulate adenylate cyclase in osteoblastic cells. J. Clin. Invest. 72:1511-1515.

36. Harinck, H. I. J., O. L. M. Bijvoet, and A. S. T. Plantingh. 1987. Role of bone and kidney in tumor-induced hypercalcemia and its treatment with bisphosphonate and sodium chloride. Am. J. Med. 82:1133-1142.

37. Ralston, S. H., M. D. Gardner, F. J. Dryburgh, R. A. Cowan, and I. T. Boyle. 1986. Influence of urinary sodium excretion on the clinical assessment of renal tubular calcium reabsorption in hypercalcaemic man. J. Clin. Pathol. 39:641-646.

38. Durie, B. G. M., S. E. Salmon, and G. R. Mundy. 1981. Relation of osteoclast activating factor production to the extent of bone disease in multiple myeloma. Br. J. Haematol. 47:21-30.

39. Ralston, S. H., B. F. Boyce, R. A. Cowan, M. D. Gardner, W. D. Fraser, and I. T. Boyle. 1988. Contrasting mechanisms of hypercalcaemia in early and advanced humoral hypercalcemia of malignancy. Calcif. Tissue Int. 42(Suppl.): 181.

40. Mundy, G. R., and T. J. Martin. 1982. Hypercalcemia of malignancy: pathogenesis and treatment. Metab. Clin. Exp. 31:1247-1277.

41. Eilon, G., and G. R. Mundy. 1978. Direct resorption of bone by human breast cancer cells in vivo. Nature (Lond.). 276:726-728.

42. Galasko, C. S. B., and A. Bennett. 1976. Relationship of bone destruction in skeletal metastases to osteoclast activation and prostaglandins. Nature (Lond.). 263:508-510.

43. Valentin-Opran, A., G. Eilon, S. Saez, and G. R. Mundy. 1985. Estrogens and antiestrogens stimulate release of bone resorbing activity by cultured human breast cancer cells. J. Clin. Invest. 75:726-731.

44. Percival, R. L., A. J. P. Yates, R. E. S. Gray, J. Galloway, K. Rogers, F. E. Neal, and J. A. Kanis. 1985. Mechanisms of malignant hypercalcemia in carcinoma of the breast. Br. Med. J. 291:776-779.

45. Breslau, N. A., J. L. McGuire, J. E. Zerwekh, E. P. Frenkel, and C. Y. C. Pak. 1984. Hypercalcemia associated with increased serum calcitriol levels in three patients with lymphoma. Ann. Intern. Med. 100:1-7.

46. Fetchick, D. A., D. R. Bertolini, P. S. Sarin, S. T. Weintraub, G. R. Mundy, and J. D. Dunn. 1986. Production of 1,25-dihydroxyvitamin D by human T-cell lymphotrophic virus-I transformed lymphocytes. J. Clin. Invest. 78:592-596.

47. Roodman, G. D., K. J. Ibbotson, B. R. MacDonald, T. J. Keuhl, and G. R. Mundy. 1985. 1,25(OH) $)_{2}$ vitamin $D_{3}$ causes formation of multinucleated cells with osteoclast characteristics in cultures of primate narrow. Proc. Natl. Acad. Sci. USA. 82:8213-8217.

48. Manolagas, S. C., D. M. Provvedini, and C. Tsoukas. 1985. Interactions of 1,25 dihydroxyvitamin $D_{3}$ and the immune system. Mol. Cell. Endocrinol. 43:113-122.

49. Sato, K., H. Miumra, D. C. Han, T. Kariuchi, T. Ueyama, H. Ohkawa, T. Okabe, Y. Kondo, N. Ohsawa, T. Tsushima, and K. Shizume. 1986. Production of bone resorbing activity and colony stimulating activity in vivo and in vitro by a human squamous cell carcinoma associated with hypercalcemia and leukocytosis. J. Clin. Invest. 78:145-154.

50. Parfitt, A. M. 1987. Bone and plasma calcium homeostasis. Bone. 8:S1-S8.

51. Staub, J. F., P. Tracqui, P. Brezillon, G. Milhaud, and A. M. Perault-Staub. 1988. Calcium metabolism in the rat: a temporal selforganized model. Am. J. Physiol. 254:R134-R149. 